\title{
Take-off characteristics for NACA 4612 aerofoil in a twin-wing configuration with optimum angles of attack
}

\author{
Kenneth L. Witcher ${ }^{1}$, Ian R. McAndrew ${ }^{2, *}$, and Elena Vishnevskaya $^{3}$ \\ ${ }^{1}$ Embry Riddle Aeronautical University - Worldwide, Florida USA \\ ${ }^{2}$ Embry Riddle Aeronautical University - Worldwide, Earnley, UK \\ ${ }^{3}$ Embry Riddle Aeronautical University - Worldwide, Bitburg, Germany
}

\begin{abstract}
Unmanned Aerial Vehicles are used generally at low levels and speeds. The research reported in this article investigates the possible use of twin-wing designs for higher altitudes with a focus on the possible lift capable for either short runways or high payloads. The wing aerofoil and unique Angles of Attack, AoA, are set $5^{\circ}$ on the upper wing and $10^{\circ}$ on the lower. There is a positive upper wing stagger of $50 \%$ of the chord length at height separation of 1 chord. These parameters have been established from previous research and this research investigates how they generate lift at take-off and what lift and drag properties exist. It also determines if these parameters are in-line with those for high altitude flight.
\end{abstract}

\section{Introduction and background}

Unmanned Aerial Vehicles, UAV, are used for many things nowadays and their possibilities are increasing. One area they are not classically designed to operate is at high altitudes above current commercial aircraft operational levels. The research reported here builds upon the use of twin-wing UAV to achieve high altitudes at relatively low speeds and applies the principles learned to review the requirements for take-off [1]. UAVs are usually low based technology including the power units and control surfaces. Most have fixed pitched propellers and no high-lift devices. This research effort aims to determine if high altitude twin-wings are equally practical for other stages of flight [2].

Take-off can be classified in three ways: shortest runway length needed; maximum take-off weight, MTOW; and stall conditions at take-off speed. Whilst the first two can be accommodated, the third condition is critical to ensure safety and reliability. UAVs being remotely piloted cannot have instantaneous feedback to respond when emergencies occur; thus, take-off stability is a significant part of design [3].

\section{Literature and theory}

\footnotetext{
* Corresponding author: McAnd4f1@erau.edu
} 
Take-off has different aerodynamic considerations than other stages of flight. Lift needs to be generated quickly, as this happens the drag increases proportionally. At low speeds the drag is not significant and this is why acceleration can happen quickly [4]. Drag and lift combined influence stall, and it is stall that is critical when taking-off. Stall will be independent of speed as the Angle of Attack, AoA, increases and loss of lift will result in aircraft departure of controlled flight at take-off [5]. Lift generated on twin-wing aircraft has separate airflow consideration, here, combined with the flow between the underneath of the lower wing and the runway. The influences of the runway and the twin-wings are complex with many different inputs that may interact with others to compound the influences [6].

Previous research has been based on using a NACA 6214, shown below in figure 1, which is in a twin-wing configuration. This aerofoil is used for gliders needing high lift and has many benefits; in particular the thickness is indicative for higher lift at low speeds. This aerofoil would not be ideal for higher speeds in the transonic range; and this is one of the principal reasons it has been used in previous research.

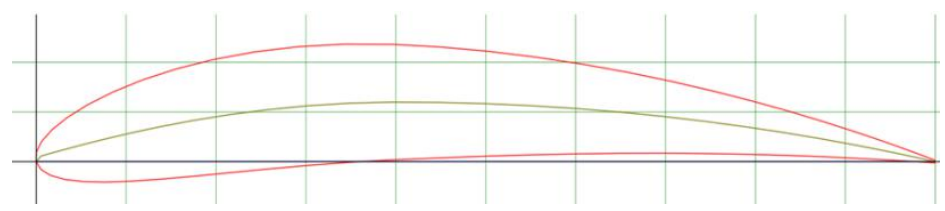

Fig. 1. NACA 4612 aerofoil section.

\section{Methodology}

A Computational Fluid Dynamics, CFD, simulation will be used with MicroCDF ® 2D. Simulation needs verifying, this has been covered in previous research, see reference 1 . Wind tunnel length of $12.5 \mathrm{~m}$; model length $3.84 \mathrm{~m}$ and resolution $1250 \times 800$. Take-off configurations are accommodated by setting the ground effects on the model [7]. Model simulated set as smooth and the different speeds range from Mach 0.06 to 0.2 and shown in table 1 below. These take-off speeds are empirically set to cover a range below, at take-off and in excess of take-off to determine the Lift, Drag, and potential stability [8]. The AoA of the upper wing is set at $5^{\circ}$ and the lower at $10^{\circ}$ as these were established for optimum flight conditions.

\section{Results and discussions}

Each simulation used the same parameters as discussed with the exception of changes to Mach numbers. Results for each speed were recorded in Mach; density; pressure and temperature. Additionally, the stream lines and force lines were recorded and the significant data are shown and discussed below.

Table 1. Simulation data for twin-wing at various Mach speeds.

\begin{tabular}{|c|c|c|c|c|c|c|c|c|}
\hline Mach & $\mathbf{0 . 0 6}$ & $\mathbf{0 . 0 9}$ & $\mathbf{0 . 1}$ & $\mathbf{0 . 1 1}$ & $\mathbf{0 . 1 2}$ & $\mathbf{0 . 1 3}$ & $\mathbf{0 . 1 5}$ & $\mathbf{0 . 2}$ \\
\hline 2D Lift Force N/m & $1.78 \mathrm{E} 5$ & $2.3 \mathrm{E} 3$ & $3.2 \mathrm{E} 3$ & $41 \mathrm{E} 3$ & $4.9 \mathrm{E} 3$ & $5.9 \mathrm{E} 3$ & $8.3 \mathrm{E} 3$ & $1.6 \mathrm{E} 4$ \\
\hline 2D Drag Force N/m & $1.49 \mathrm{E} 4$ & $3.6 \mathrm{E} 2$ & $3.6 \mathrm{E} 2$ & $4.2 \mathrm{E} 2$ & $4.8 \mathrm{E} 2$ & $5.4 \mathrm{E} 2$ & $6.8 \mathrm{E} 2$ & $1 \mathrm{E} 3$ \\
\hline 2D Coefficient Lift & 1.8 & 1.18 & 1.18 & 1.18 & 1.2 & 1.3 & 1.35 & 1.47 \\
\hline 2D Coefficient & 1.5 & 0.13 & 0.13 & 0.13 & 0.13 & 0.12 & 0.11 & 0.1 \\
\hline Pitch & 1.5 & 0.11 & 0.11 & 0.11 & 0.13 & 0.11 & 0.12 & 0.13 \\
\hline
\end{tabular}


Above, the values of both lift and drag forces, in $\mathrm{N} / \mathrm{m}$, and coefficients for lift and drag are shown for each Mach value. Figure 2, below, shows the Mach speed variations for Mach at 0.09. The key to the speeds shown is on the left of the figure. Nominal speed of Mach 0.09 and the range seen is from Mach 0.032 to 0.136 . Theory of lift relates to the speed: the faster the speed, the lower the static pressure [9]. The faster the speed on the upper surface in relationship to the lower surface, then the greater the lift. Interestingly, the lift on the lower wing is not significantly lower than the upper, showing the two wings are not significantly causing compound flow problems. In the wake of the lower wing is a high speed section that is trailing and clearly on the runway surface. This would wash-up anything on the runway and might affect the airflow of any UAV taking off immediately behind. It also would induce more drag than expected. The downwash and trailing high speed on the runway will have practical concerns for the use on airfields with a nonstandard surface.

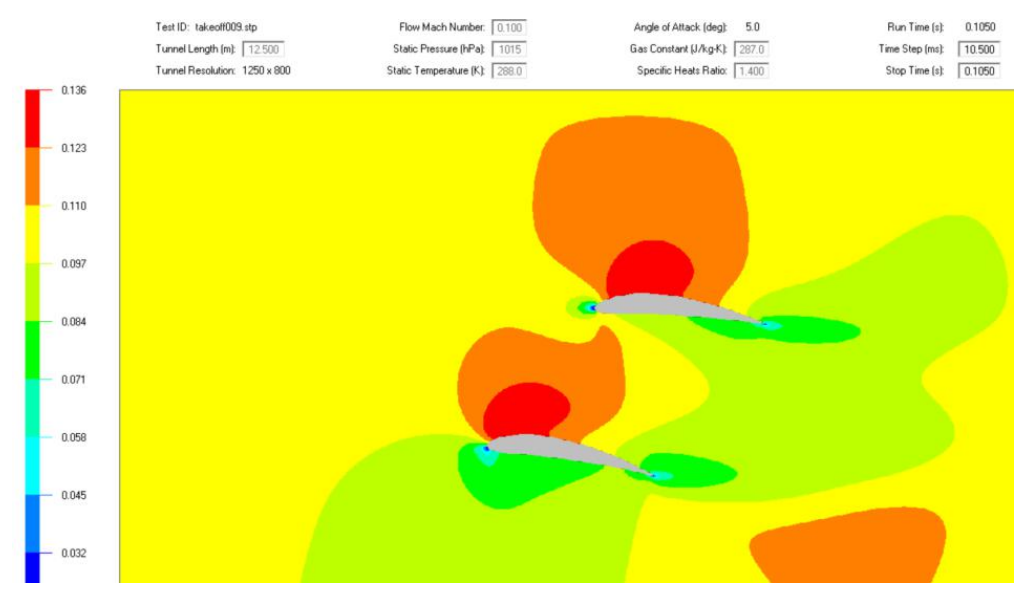

Fig. 2. Mach 0.09 simulation results.

Figure 3 shows the Mach number distribution, on the left, at a forward speed of Mach 0.2. This is expected to be substantially greater than take-off speed. There is no downwash causing the high speeds passing over the runway. This might be as the speed increases the resulting pressure on the runway creates a higher static pressure slowing any passing air. Leading edge speeds at Mach 0.2 are more influenced and create a generally more stable distribution [10]. On the right are the pressure profiles. The lower wing is generating greater differential pressure with a humongous distribution on the whole of the underside. On the upper wing the lower side is split in two pressure levels and the lowest differential pressure is approximately at the maximum chord thickness.

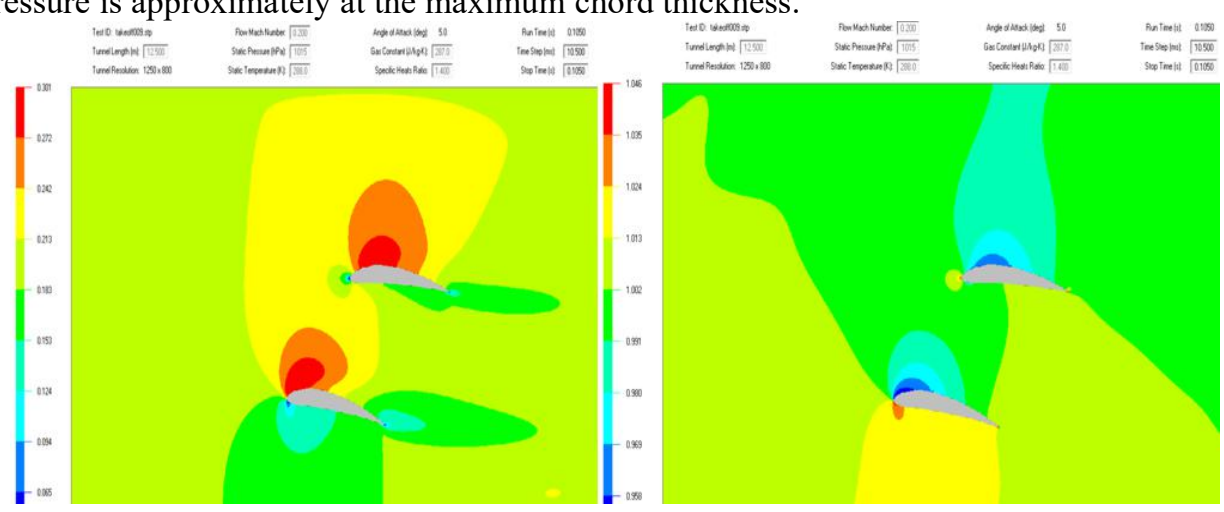

Fig. 3. Mach 0.2 simulation results for Mach and pressure. 
Streamlines for the Mach 0.2 shows in figure 4, below, the leading edge disturbance, on the right, and how far behind the trailing edge where laminar flow returns [11]. These match and support the results of pressure distribution in figure 3. All the main influences of the lower wing are directly under the length of the chord; and, in this case, add to the pressure differential. On the left side is the temperature profile, lower temperature approximately relates to density and, thus, pressure [12]. The higher AoA on the lower wing influences the temperature above its horizon, and directly underneath. The aforementioned is less likely if the ground effect was removed. Trailing edges at the midpoint soon revert to normal temperature and then those directly behind these edges.

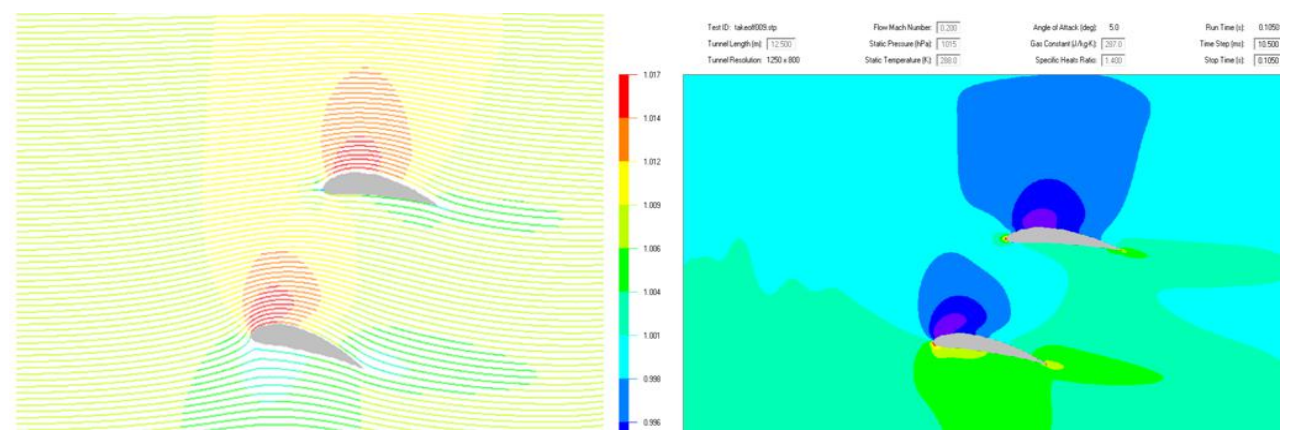

Fig. 4. Mach 0.2 laminar flow lines at lading and trailing edges.

Results shown in table 1 shows the principal results for all the speeds simulated at the take-off speeds regardless of the actual speed when take-off is capable. Clearly, Mach 0.2 exceeds what was expected and the influences of lift and drag are shown in figure 5. Lift and drag are plotted for the forces in $\mathrm{N} / \mathrm{m}$. The primary axis shows the forces for the lift and the secondary vertical axis, right those for drag. At lower speeds the lift to drag ration is at its greatest, which is not surprising given drag is negligible at lower speeds, especially below Mach $0.07(50 \mathrm{mph})$ where aerodynamic streamlining does not add advantage, table 1 at $0.06 \mathrm{M}$ values are ignored here as potentially spurious. As the speeds increase, so do the lift and drag, and increases proportionally until Mach 0.13, when this increase is notably higher and approximately follows an exponential increase. Between Mach 0.15 and 0.2 the increase in drag exceeds the rate of change for lift and is indicative on stall symptoms; suggesting this configuration is where stall is occurring. Further research and data analysis would be needed to verify and relate all the parameters. Determining an AoA not within the stall zone will enable optimum take-off speed to be established.

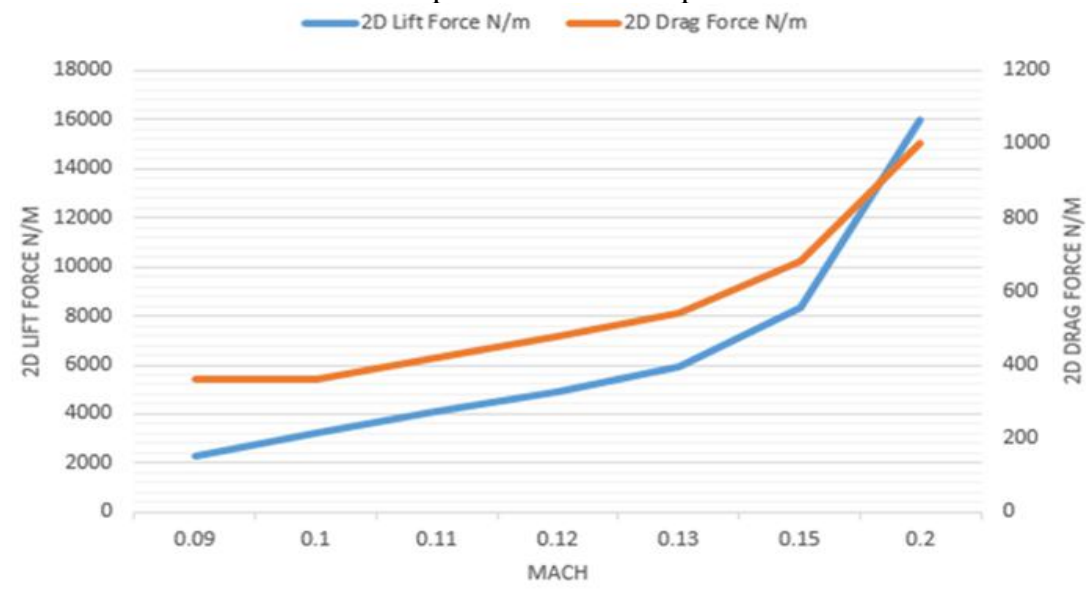

Fig. 5. Lift and drag at various Mach speeds. 
Pitch, shown in table 1, is shown for all Mach numbers and the effective lift of each stage is seen to be identical and consistent, a summary of this is shown in figure 6 below.. This suggests no natural pitch up at take-off speed, it will 'drift' with the lift generated, and this is indicative of stability.

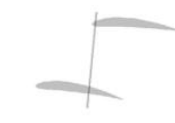

Mach 0.06

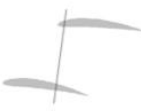

0.09

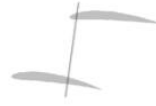

0.1

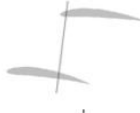

0.11

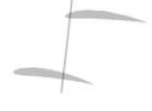

0.12

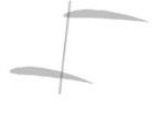

0.13

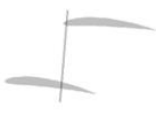

0.2

Fig. 6. Effective pitch at various Mach speeds.

\section{Conclusions and future work}

This research reported has simulated the take-off speeds for a twin-wing configuration with the upper wing at an AoA $5^{\circ}$ and the lower at $10^{\circ}$. Mach, density, pressure and temperatures variations were determined and thus, lift and drag values. The ground effects and influences on drag have shown the lift is considerably greater in the ranges of AoA that would be both practical and acceptable for take-off. Pitch is not changing as speed increases through all the speeds. What is not known is the AoA during the start and range of stall velocities. Future work will concentrate on this and also how a particular wing profile will be effected by the form at a fuselage and wing tip vortices.

\section{References}

1. McAndrew, I, Vishnevskaya, E. and Carruthers, A. (2017) TWIN-WING DESIGN OPTIONS USED FOR UNMANNED AERIAL VEHICLES TO ACHIEVE HIGH ALTITUDES AT LOW SPEEDS, International Journal of Research \& Development Organisation, Nov issue, p11-20.

2. McAndrew, I. R, Navarro, E. \& Witcher, K (2017), INTERNATIONAL JOURNAL OF MATERIALS, MECHATRONICS AND MANUFACTURING, Propeller Design Requirements for Quadcopters Utilizing Variable Pitch Propellers, Volume 6, Number 1.

3. Anderson, J., Fundamentals of Aerodynamics, McGraw-Hill Education, 2010, 9780073398105.

4. Roskin, J., (1997) Airplane Aerodynamics and Performance, Darcorporation.

5. Houghton, E., Carpenter, P., Collicott, S., and Valentine, D., (2016) Aerodynamics for Engineering Students, 7th Ed., Butterworth Hill.

6. Witcher, K., McAndrew, I. R., and Vishnevskaya, E, (2017) Aerodynamic Analysis of Low Speed Wing Design using Taguchi L9 Orthogonal Array, International Conference on Mechanical and Aerospace Engineering, Yokohama, Japan, 29th -31 st Dec.

7. Moran, J (2003). An introduction to theoretical and computational aerodynamics. Dover. p. 7. ISBN 0-486-42879-6.

8. Halliday, D., (2014) Fundamentals of Physics, Wiley, UK

9. McAndrew, I. R., Carruthers, A. \& Navarro, E. (2014). HYPERSONIC UNMANNED AERIAL VEHICLES: A CASE FOR RAPID DEPLOYMENT OF SPECIALISED CARGO. International Journal of Unmanned Systems Engineering (Vol. 2, No. 3, pp. 
80-85). ISBN: 978-1-907980-06-0. World Congress on Unmanned Systems Engineering, University of Oxford, Oxford, UK. 30th July - 1st August.

10. Clarke, M., Norman, N., Smith, S., (2015), Construction and Analysis of Subsonic Airfoils for Wind Tunnel Testing, ASME 2015 International Mechanical Engineering Congress \& Exposition, ASME International Undergraduate Research and Design Expo.

11. Sareen, A., Deters, R.W., Henry, S.P., \& Selig, M.S. (2014). Drag reduction using riblet film applied to airfoils for wind turbines. ASME Journal of Solar Energy Engineering, 136(2), 021007-1 - 021007-8. doi:10.1115/1.4024982.

12. Sumwalt, R., Cross, D., \& Lessard, D. (2015). Examining how breakdowns in pilot monitoring of the aircraft flight path can lead to flight path deviations. International Journal of Aviation, Aeronautics, and Aerospace, 2(3), Article 8. Retrieved from http://commons.erau.edu/ijaaa/vol2/iss3/8. 